\section{Economic evaluation in the context of rare diseases: is it possible?}

\author{
Avaliação econômica no âmbito das doenças raras: \\ isto é possível?
}

\section{Evaluación económica en el contexto de enfermedades raras: ¿es posible?}

\author{
${ }^{1}$ Faculdade de Ceilândia, \\ Universidade de Brasília, \\ Ceilândia, Brasil. \\ 2 Centro de Pesquisa em \\ Álcool e Drogas, Universidade \\ Federal do Rio Grande do Sul, \\ Porto Alegre, Brasil. \\ 3 Hospital de Clínicas de \\ Porto Alegre, Universidade \\ Federal do Rio Grande do Sul, \\ Porto Alegre, Brasil.

\section{Correspondence} \\ E. N. Silva \\ Faculdade de Ceilândia, \\ Universidade de Brasília. \\ Centro Metropolitano, \\ Conjunto A, Lote 01 , \\ Ceilândia, DF 72220-900, \\ Brasil. \\ evertonsilva@unb.br
}




\section{Introduction}

Patients with rare diseases generally suffer from an insufficient supply of medications for their needs 1 , due mainly to the low prevalence of these diseases 2 . As a result, investments in research and development $(\mathrm{R} \& \mathrm{D})$ for rare diseases are borne by a small number of potential consumers, resulting in prohibitive prices for patients and healthcare systems, which resist supplying the drugs free of cost to the population. Policymakers contend that the technologies supplied to patients with rare conditions fail to meet all the requirements for incorporation and reimbursement by health systems, that is $3,4,5,6$ : (i) the evidence is insufficient on their safety and efficacy; (ii) the incremental cost-effectiveness ratios that signal efficiency in allocating scarce resources are generally higher than the thresholds commonly accepted by health systems; and (iii) there is a high opportunity cost to provide these technologies to patients with rare diseases, since the same budget funds could treat more patients with common diseases, or those that affect a large contingent of the population (high prevalence).

Researchers and policymakers have focused on rare diseases to determine whether they should be awarded different status from that of other diseases, especially in the economic evaluation of related health technologies. This article uses a narrative review to analyze the available evidence on rare diseases and economic evaluation, in order to determine whether the latter is applicable. In other words, the aim is to indicate whether there is a need for a new methodological approach to the incorporation of technologies for rare diseases, beyond the existing provisions in Brazil's Law n. 12,401 of 20117. Secondary objectives include the characterization of rare diseases and the policies adopted for them; analysis of rare diseases according to the principles of research ethics; description of the theoretical basis for economic evaluation studies; and a literature review on the adequacy of economic evaluation as a decision-making tool for policies on rare diseases.

\section{Method and references}

We conducted a narrative review of the literature to select articles, documents, and reports on the adequacy of economic evaluation studies in the decision-making process on the incorporation of technologies for rare diseases. The following health descriptors were selected: rare diseases; orphan drugs; orphan diseases; rare diseases; eco- nomic evaluation; cost-effectiveness; health economics; health technology assessment.

The following databases were used: MEDLINE, via PubMed, Centre for Review and Dissemination (CRD) of the University of York (York, United Kingdom), LILACS, and SciELO. Since the theme involves the decision-making process at the health management level, it is necessary to search for institutions that focus on this process. We opted to use Google Scholar, since it is more sensitive for capturing non-indexed documents. There was no limitation on the year or language of publication.

\section{Development}

The study's results are divided into subsections, according to the secondary objectives listed in the introduction.

\section{Definition of rare diseases and policies adopted to overcome their health and economic consequences}

A rare disease is a health condition that occurs infrequently or rarely in the general population. A large proportion of rare diseases have genetic origins, accounting for some $80 \%$ of the total according to estimates by EURORDIS 2005 8. Other rare diseases include rare cancers, autoimmune diseases, congenital malformations, infectious and toxic diseases, or rare manifestations of common diseases caused by environmental exposure during pregnancy or throughout life 9 .

Manifestations of rare diseases can occur either at birth or during childhood (Williams and Prader-Willi syndromes and retinoblastoma) or at any phase in adulthood (Huntington disease, Creutzfeldt-Jacob disease, and amyotrophic lateral sclerosis). Fifty percent of rare diseases manifest in adulthood. Clinically, rare diseases include a large number and wide range of health conditions and symptoms, varying not only from one disease to another, but within the same disease. The same disease can have many different clinical manifestations in different patients 8 .

Despite differences in their severity and expression, nearly all rare diseases involve a significant reduction in life expectancy. Many rare diseases are complex, degenerative, and chronically debilitating, affecting the person's physical, mental, sensory, and behavioral capacities. However, in some cases, when diagnosed in time and treated correctly, they allow living a normal life 10 .

Although the rarity of the diseases, there are numerous rare diseases (an estimated 5,000 to 8,000 worldwide) 11 . In the European Union 
alone, an estimated 30 million persons have some type of rare disease, or $6 \%$ to $8 \%$ of the entire population, while an estimated 25 million North Americans have rare diseases.8,9,11

There is no single definition for rare disease. Health systems generally define rare diseases on the basis of prevalence or number of patients or subjects. In the European Union, a disease is designated as rare when it affects fewer than 5 to 10 thousand persons; in the United States, when it affects fewer than 200 thousand persons in the entire country (or 7.5/10 thousand inhabitants according to the Orphan Drug Act passed by the U.S. Congress in 1983) 12,13 .

In addition, only a few rare diseases - about 100 - approach the threshold of 5 to 10 thousand persons, like Brugada syndrome, Guillain-Barré syndrome, scleroderma, or neural tube defects. Most other rare diseases affect fewer patients some with less than 0.1 per 10,000 inhabitants, like hemophilias, Ewing sarcoma, Duchennne muscular dystrophy, or von Hippel-Lindau disease, which are considered "very rare" or "ultrarare" diseases. Table 1 summarizes the criteria adopted by selected countries and regions.

Among the Latin American countries, Colombia recently lowered the threshold for rare diseases from 5/10,000 to 2/10,000 inhabitants (Law on Policy Regulation for Rare Diseases - Law n. 1,392 of 2010 and Law n. 1,438 of 2011). Meanwhile, Peru passed a law on rare diseases in 2011 that did not specify any epidemiological criterion, but defined rare diseases as those that seriously affect life, have low prevalence, and involve specific difficulties with diagnosis and follow-up 14.

Brazil lacks official estimates on the number of patients with rare diseases and does not adopt an epidemiological definition. By applying the European Union's estimate of $6 \%$ to $8 \%$ of the population, an estimated 13 to 15 million Brazilians have rare diseases. According to the Brazilian Health Surveillance Agency (ANVISA) 15, "Rare or orphan diseases are those that affect small numbers of persons within the general population." This definition exists in order to supply the specific drugs 16,17. However, the Brazilian Ministry of Health has already developed and published Clinical Protocols and Therapeutic Guidelines for 26 rare diseases, including amyotrophic lateral sclerosis, congenital adrenal hyperplasia, Guillain-Barré syndrome, Gaucher's disease, and Wilson's disease, among others.

Due to the low prevalence of rare diseases, the private sector tends to view the development of treatment for them as economically unattractive, which can create a situation of unequal access between patients with rare as opposed to common diseases 2 . The patient population for orphan drugs is very small, so the costs of research and development are covered by only a few patients in treatment 1 . However, audits in the Genzyme Corporation's accounts suggest that the costs of developing orphan drugs are lower than those of other drugs, since fewer patients are enrolled in the clinical trials 1 . But the small number of patients also reduces the quality of epidemiological evidence, so long-term projections on the safety and efficacy of these drugs is less reliable, thus hindering decision-making on their incorporation or reimbursement by health systems.

Until the 1980s, few drugs had been developed for the treatment of rare diseases, leaving patients with only palliative treatment in nearly all cases, and when the drugs were in supply, the

Table 1

Definition of rare diseases by country or region.

\begin{tabular}{lcc}
\hline Country/Region & $\begin{array}{c}\text { Criteria for definition of rare } \\
\text { disease (affected population) }\end{array}$ & Prevalence per 10,000 inhabitants \\
\hline Australia & $<2,000$ & 1.1 \\
Colombia & - & 2.0 \\
United States & $<200,000$ & $7.5(7.0)$ \\
Japan & $<50,000$ & $4.0(2.5)$ \\
WHO & $<215,000$ & 6.5 \\
European Union & $<1,000$ & 5.0 \\
United Kingdom (ultra-rare) & & 0.18 \\
\hline
\end{tabular}

WHO: World Health Organization.

Source: adapted from McCabe et al. 5 .

Note: values in parentheses based on studies from Rosselli \& Rueda 14 and Hughes et al. 19. 
pharmaceutical companies suffered financial losses 12. In 1982 the U.S. Food and Drug Administration (FDA) created a specific sector for these drugs, and in 1983 the U.S. Congress passed the Orphan Drug Act, which not only defined "orphan" diseases but also created incentives for the development of drugs and other related technologies, in the form of special government credit lines and reduced taxes. The law also provides for special research protocols and rapid approval for these technologies, in addition to guaranteeing seven-year market exclusivity for the approved drugs 12,18 .

Besides the United States, Japan, Australia, and more recently the European Union have developed policies with supply-side incentives for treatment of rare diseases (Table 2).

Policies in these countries have adopted tax incentives (except in Australia), rapid approval of drugs for clinical use, market exclusivity, and assistance in conducting approval procedures. The impact of these measures can be seen in the number of drugs developed and approved since the regulations were passed in each country (Table 3). Still, these policies do not guarantee demand, since they do not require reimbursement for treatment at any price offered by the companies. Each country has clear rules on the incorporation of the technologies into their so- cial protection systems, and some consider incremental cost-effectiveness ratios in addition to clinical evidence 19 .

In 2010, Colombia passed regulatory legislation on treatment of rare and ultra-rare diseases (Law n. 1,392 of 2010 and Law n. 1,438 of 2011) in addition to criteria for their definition (Table 1). The legislation provides for biannual updating of the list of diseases that meet the established criteria and guarantees coverage for all Colombians with rare diseases, through funding for diagnosis and treatment, including medication and procedures or other necessary healthcare services. The legislation also determines the sources of such funding and authorizes the Federal government to adopt a system for drug purchases, which can be centralized 14 .

As reported by Rosselli \& Rueda 14, Peru enacted its law on rare diseases in 2011 without setting an epidemiological threshold for their definition. However, the law specifically mentions the importance of including early diagnosis of rare diseases in the medical school curriculum and the creation of a national patient registry. The country also guarantees treatment through purchases of the drugs as a priority budget item (Law n. 29,698 - Peruvian National Congress).

The Brazilian Federal government launched the National Policy for Comprehensive Care in

Table 2

Specific legislation for rare diseases, by country and region.

\begin{tabular}{|c|c|c|c|c|c|c|}
\hline \multirow{2}{*}{$\begin{array}{l}\text { Country/ } \\
\text { Region }\end{array}$} & \multirow[t]{2}{*}{ Legislation } & \multicolumn{5}{|c|}{ Provisions in legislation for rare diseases } \\
\hline & & Tax incentives & $\begin{array}{c}\text { Rapid evaluation } \\
\text { and approval of } \\
\text { drugs }\end{array}$ & Market exclusivity & $\begin{array}{l}\text { Assistance with } \\
\text { approval }\end{array}$ & Other \\
\hline Australia & $\begin{array}{c}\text { Australian Orphan } \\
\text { Drugs Program } \\
\text { (1997) }\end{array}$ & No & Yes & Yes & Yes & $\begin{array}{l}\text { Submission } \\
\text { reviewed every } 12 \\
\text { months }\end{array}$ \\
\hline United States & $\begin{array}{c}\text { Orphan Drug Act } \\
\text { (1983) }\end{array}$ & Yes & Yes & Yes & Yes & NA \\
\hline Japan & $\begin{array}{c}\text { Orphan Drug } \\
\text { Regulation (1993) }\end{array}$ & Yes & Yes & Yes & Yes & $\begin{array}{l}\text { Partial } \\
\text { reimbursement } \\
\text { for development } \\
\text { costs; extended } \\
\text { registration period }\end{array}$ \\
\hline $\begin{array}{l}\text { European } \\
\text { Union }\end{array}$ & $\begin{array}{l}\text { Regulation n. } 141 \\
\text { (2000) }\end{array}$ & Yes & Yes & Yes & Yes & NA \\
\hline
\end{tabular}

NA: not applicable.

Source: adapted from Panju \& Bell 6 . 
Impact of specific legislation for rare diseases, by country or region.

\begin{tabular}{lccc}
\hline $\begin{array}{l}\text { Country/ } \\
\text { Region }\end{array}$ & Legislation & \multicolumn{1}{c}{ Number of orphan drugs } \\
& & Developed & Approved \\
\hline Australia & Australian Orphan Drugs Program (1997) & $180(2010)$ & $62(2010)$ \\
United States & Orphan Drug Act (1983) & $2,194(2010)$ & $350(2010)$ \\
Japan & Orphan Drug Regulation (1993) & $167(2004)$ & $95(2004)$ \\
European & Regulation n. 141 (2000) & $664(2010)$ & $51(2010)$ \\
Union & & & \\
\hline
\end{tabular}

Source: adapted from Panju \& Bell 6

Note: the years in parentheses in the last two columns are the last years tabulated.

Clinical Genetics in 2009, which includes the Clinical Protocols and Treatment Guidelines for rare diseases under the Brazilian Unified National Health System (SUS) and the supply of 45 drugs and surgical and clinical treatments. Although the National Health System does not have specific legislation for the purpose, it provides more than 72,000 physician consultations and 560,000 laboratory procedures per year for the treatment and diagnosis of rare diseases, with annual expenditures of more than BRL 4 million.

\section{Rare diseases and research ethics}

Research ethics are another important point, especially relating to access to technologies after conclusion of the trials. The compensation for patients that voluntarily bear the risk of submitting to a research protocol to collaborate in scientific and technological development includes their right to receive treatments that have proven beneficial at the conclusion of the trial.

Since 2000, the World Medical Association (WMA) has taken a stand for post-trial access to technologies by research participants. Among other ethical principles that orient biomedical research involving human subjects, the WMA recommended that "At the conclusion of the study, every patient entered into the study should be assured of access to the best proven prophylactic, diagnostic, and therapeutic methods identified by the study" (Declaration of Helsinki, 2000, paragraph 30). This position was ratified in the 2008 revision: "At the conclusion of the study, patients entered into the study are entitled to be informed about the outcome of the study and to share any benefits that result from it, for example, access to interventions identified as beneficial in the study or to other appropriate care or benefits" (Declaration of Helsinki, 2008, paragraph 33).
In Brazil, the National Health Council regulates aspects related to studies that involve human subjects. Ruling $n$. 196/96 mentions this topic directly or indirectly in several of its paragraphs 20, stating for example that "research subjects are assured of the benefits resulting from the research project, either in terms of social return or access to research procedures, products, or agents" (Ruling n. 196/96, paragraph III.3.P).

Cohen et al. 21 analyzed 312 clinical trials on interventions related to HIV/AIDS, tuberculosis, and malaria in the mid-2000s. Of these, 36 (12\%) were conducted in Latin American countries, including Brazil (9 trials). Considering all the clinical studies, only $1 \%$ contained information on supply of the treatment after conclusion of the study (which shows their non-compliance with this principle).

The guarantee of access to interventions at the conclusion of studies on rare diseases can limit their economic attractiveness. An example is type I mucopolysaccharidosis, a lysosomal storage disease caused by deficient activity in the enzyme $\alpha$ L-iduronidase (and with an estimated 87 patients identified in Brazil) 16. If the principle of supplying the drug to research subjects were enforced, and if this clinical trial had a representative sample size, practically all the potential demand for the drug would be consumed by post-trial access for the study volunteers. In other words, the cost would be transferred to the patients that did not participate in the study, mak ing the price of the drug even more prohibitive.

\section{Economic evaluation of health technologies}

A growing number of countries are adopting health technology assessment studies in their respective health systems, which includes economic evaluation studies, even writing them for- 
mally into their legal frameworks 22,23. In other words, the scientific evidence on various aspects of health technologies (safety, efficacy, accuracy, effectiveness, efficiency, feasibility) is taken into account in the decision-making process on their incorporation or exclusion, changes in clinical practice, and ethical, social, and political issues.

Economic evaluation is theoretically based on welfare economics, in which individuals maximize their utilities. In order to verify this, a set of conditions must be met, as established in general equilibrium models (expected utility theory, rationality of economic players in the face of uncertainty, Pareto optimality) 24 . According to this concept, social welfare is obtained as the sum of individual utilities 25 . The greater the aggregate sum of utilities, the greater society's welfare.

Importantly, however, this theoretical basis does not imply a judgment on the fairness or any other aspects related to the distribution of the sum of utilities among society's individuals 26 . Suffice it for one individual - or a few - to have their utilities increased for Pareto optimality to be reached, as long as the other individuals do not fare worse when compared to the previous situation.

This point becomes controversial in the context of health systems that adopt notions of equity in their jurisdictions with the aim of promoting fair inequalities: in other words, unequal treatment is fair when it benefits the neediest individuals 27. In this context, particular attention has been given to rare diseases, due to the characteristics mentioned previously. According to some authors, patients with rare diseases have a greater need for healthcare due to their health vulnerabilities and the high cost of treatment, which is prohibitive for most families 16 . The study by Souza et al. 16 (p. 3450) argues further that "drugs for rare diseases could be included on Ministry of Health lists by adopting special criteria, using less utilitarian principles and taking into account both the patients' vulnerability and society's position in relation to this inclusion, setting priorities for this purpose."

A counterpoint to this argument lies in the idiosyncrasy in decision-makers' definitions of health needs 4 , which are not always in tune with society's moral and ethical principles. In addition, there is no widely accepted criterion in the literature that can be used to weigh individuals' expected utilities, in the sense of assigning greater weight to persons with the greatest health needs. Therefore, economic evaluation does not usually weigh the utilities of individuals in a society asymmetrically 24 ; everyone is treated equally, which is a Constitutional principle in the Brazilian case.
Methods used to complement economic evaluation studies

Based on the premise that economic evaluation studies are sustained by efficiency measures (optimal allocation of scarce resources in an economy) and by society's values, it has been argued in the health economics literature that conventional methods (cost-utility studies) may not reflect society's preferences, which could bias the decision-making process. For example, some studies would have a relatively small incremental ratio (for example, studies on the removal of tattoos or treatment of male impotence), and society would thus assign low priority to them. Meanwhile, technologies with incremental ratios above the conventional cost-effectiveness ratios would enjoy wider acceptance by society 1 .

This happens because the instruments normally used to measure quality-adjusted life years (QALYs) - like Visual Analogue Scale, Standard Gamble, Time Trade-Off - are limited to asking participants how they evaluate given health states ${ }^{28}$. The problem arises when QALYs are used to extrapolate society's preferences concerning the allocation (distribution) of scarce resources among different population groups, since this question is not asked explicitly in the instruments used to measure QALYs 29. Other relevant variables for decision-making go unmeasured: the seriousness of health status when comparing different diseases; the existence of alternative treatments; or the impact of treatment cost on the family budget.

In addition, instruments to measure QALYs are usually applied to individuals with a given health condition (patients), rather than to all individuals (society). This could introduce biases when attempting to define society's view as a whole, namely: (i) according to the main international guidelines, economic evaluation studies should be performed from society's perspective, meaning that the instruments for measuring utilities should be applied to the general population rather than to a specific group 30,31 ; (ii) patients have their own conflicts of interest, tending to overestimate QALYs 32; and (iii) the presence of a disease can affect individuals' perceptions 33 .

Thus, new approaches could play an important role in this context, for example the Person Trade-Off method. This tool has the advantage of capturing society's values in weighing efficiency and equity 1,28 . In other words, society could give up a certain gain in health - for example, from technologies with incremental ratios within conventional standards of acceptance by the health system - given that society assigns greater value to treatments of other diseases, even if they pres- 
ent high incremental ratios for the acceptable standards.

The Person Trade-Off methodology poses a direct question to participants, such as: "If there are $X$ persons in adverse health situation $A$ and $Y$ persons in adverse health situation $B$, and you can only help (i.e., provide treatment for) one group, which group would you choose?" 29. X and $Y$ can vary until respondents feel indifferent about their desire to help. We would thus obtain a "disutility" for health condition B in relation to A expressed as $X / Y$. For example, suppose there are two groups, group A, individuals with moderate disease, and group $\mathrm{B}$, individuals with severe disease. By applying the Person Trade-Off methodology to the general public, one reaches the following result: for the same gain in health (1 QALY), the general public feels indifferent about improving the health of (or treating) 10 individuals with moderate disease and 5 individuals with severe disease; the conclusion is that the disutility of treating group B compared to group A is 0.5; since it is less than 1 , it means that society assigns greater value to health condition $\mathrm{B} 32$.

Ubel et al. 32 proposed a two-stage method to better capture societal values. The first stage consists of using conventional instruments for measuring quality-adjusted life years from the patient's perspective - individuals that really have a specified health state. The second stage assigns weights to different utility gains in order to reflect society's preferences, taking the general public into consideration rather than the patient's view. This format seeks to obtain the inherent advantages of the two groups of respondents: the patients - since they have a better understanding of the health state - and the general public - since it makes decisions under the veil of ignorance, that is, without apparent potential conflicts of interest.

In the addition to Person Trade-Off, the "Rule of Rescue" technique has been used 19 to recommend treatment of patients with rare diseases. The term expresses the social and human obligation to rescue individuals in a situation of imminent risk of death, for example rescuing a shipwrecked person on the high seas, or a lost mountain climber. A highly visible case occurred recently in Chile with 33 miners trapped hundreds of meters underground and rescued at a cost of 22 million dollars 14 .

Society in general values this type of action: few people would adopt economic logic in such a situation or question the opportunity cost as compared to using these same resources to invest in child health programs, for example.

The victim's visibility/identification in the face of an avoidable death is a key argument in the Rule of Rescue, as is deducing preferences for this type of action at a moment of shock or commotion. There is a tendency to assign priority to persons with some type of disability, even if the available treatment is less effective as compared to that for other diseases 34 . Giving priority to identifiable individuals rather than to a "statistical" life violates the hypothesis of distributive neutrality.

The Rule of Rescue prioritizes the severity of the disease over treatment effectiveness and costs, which contradicts the utilitarian logic/ ethic, overriding the choice of cost-effective interventions that maximize efficiency in the use of resources (Table 4).

\section{Final remarks}

This article aimed to obtain an overview of the economic characteristics of rare diseases to verify whether economic evaluation studies apply to this context. We used the narrative review method to analyze aspects such as: (i) definition and economic implications of rare diseases in health systems; (ii) economic policies for rare diseases; (iii) ethical issues related to rare diseases; (iv) theoretical foundations for economic evaluation studies; and (v) methods to complement economic evaluation. The following is the main evidence found here.

For the definition of rare diseases, the most widely used criterion is epidemiological. Some countries or regions quantify "rarity" (United States, Japan, Australia, European Union) while others do not, merely referring to rare diseases as those that affect a small number of persons within the general population (Brazil, Peru). Using the epidemiological parameter, the concept encompasses a wide range of diseases (a total of up to eight thousand). Characteristics that are usually shared by these diseases are a genetic cause $(80 \%)$ and a significant reduction in life expectancy. In economic terms, rarity is associated with low attractiveness for private investment, since there would supposedly be a high risk in the research and development process, together with a reduced demand for the technologies. One counterpoint to this issue was published in Forbes magazine on August 23rd, 2012, under the title Orphan Drugs: 'Rare' Opportunities to Make Money 35. The article identifies orphan drugs as great investment opportunities, since they represent $6 \%$ of all sales in the pharmaceutical industry, outstripping the growth of drugs for more prevalent diseases $(25.8 \%$ vs. $20.1 \%$, respectively). In addition, in $15 \%$ of the cases analyzed, the same drug can be registered for more than 
Rule of Rescue and Utilitarianism.

\begin{tabular}{|c|c|c|}
\hline & Rule of Rescue 19 & Utilitarianism 5 \\
\hline $\begin{array}{l}\text { Special status of the } \\
\text { disease }\end{array}$ & $\begin{array}{c}\text { Assure treatment of diseases for which } \\
\text { there is no existing treatment; severity of } \\
\text { the disease. }\end{array}$ & $\begin{array}{l}\text { Does the legislation represent society's } \\
\text { preferences? Is society willing to pay more for } \\
\text { fewer persons treated for rare diseases? }\end{array}$ \\
\hline $\begin{array}{l}\text { Evidence of } \\
\text { effectiveness }\end{array}$ & $\begin{array}{l}\text { Not possible to recruit a sufficient number } \\
\text { of patients for clinical trials; the limited } \\
\text { time frame for analysis of chronic diseases } \\
\text { requires enrollment and follow-up of } \\
\text { patients after initiating treatment. }\end{array}$ & $\begin{array}{c}\text { Some diseases have enough patients to allow } \\
\text { larger studies, e.g., Gaucher's disease - clinical } \\
\text { trials with } 12 \text { patients and } 10 \text { years after } 3,000 \\
\text { patients on medication; enrolling patients } \\
\text { does not solve the problem, since introduction } \\
\text { of therapy changes the natural history of the } \\
\text { disease. }\end{array}$ \\
\hline $\begin{array}{l}\text { Limited budget } \\
\text { impact }\end{array}$ & $\begin{array}{l}\text { Given the small number of patients, the } \\
\text { budget impact is also small. }\end{array}$ & Necessary to consider opportunity cost. \\
\hline Equity & $\begin{array}{l}\text { From the utilitarian point of view, investing } \\
\text { in patients with rare diseases is not ethical, } \\
\text { but everyone has the right to a minimum } \\
\text { level of health. }\end{array}$ & $\begin{array}{l}\text { The Rule of Rescue is not really a rule, but an } \\
\text { emotional reaction in the face of tragic events, } \\
\text { and should not orient policies; the public } \\
\text { appeal of known lives should not be worth } \\
\text { more than that of unknown lives. }\end{array}$ \\
\hline $\begin{array}{l}\text { Options for policy } \\
\text { recommendations }\end{array}$ & $\begin{array}{l}\text { Different weights (QALYs) for different } \\
\text { diseases according to prevalence; share risk } \\
\text { with industry; clinical and pharmacological } \\
\text { criteria for inclusion in treatment. }\end{array}$ & $\begin{array}{l}\text { Evidence is needed that society has } \\
\text { preferences for rare diseases; difficulties in } \\
\text { establishing when the treatment was delivered } \\
\text { successfully; difficulty in establishing clinical } \\
\text { criteria before the fact that guarantee health } \\
\text { gains. }\end{array}$ \\
\hline
\end{tabular}

QALYs: quality-adjusted life years.

one rare disease, thus expanding the potential demand.

A possible explanation for the data published in Forbes lies in the policies adopted by developed countries to encourage the supply of technologies for rare diseases by providing special credit, tax exemptions, market exclusivity, and rapid approval. In this sense, government efforts are targeted more to supporting the pharmaceutical industry than to expanding the criteria for the incorporation and availability of these technologies for potential users. In other words, registration is granted (permission for commercialization), but not the free supply of these drugs by health systems. This appears to be the strategy of the United States, the country that registers the most technologies for rare diseases, but with no commitment to incorporate them into their social protection system, given that its health system is characterized by a market focus, unlike the Brazilian system, which adopts the principles of universal and comprehensive healthcare.

Another important issue with rare diseases is the relative lack of evidence on the health effects of the available technologies for them. Factors generally identified as limiting the robustness of study results are the small number of patients enrolled in randomized clinical trials and the use of intermediate health outcomes, without analyzing the effects on patient survival or quality of life 1,36.

As for ethical issues, the Declaration of Helsinki has been criticized in the context of rare diseases, on grounds that it further reduces the economic attractiveness by supplying treatment to research subjects at the conclusion of the study. This point is controversial, since most pharmaceutical companies are large multinationals which can enroll patients in different countries where they operate, through multicenter and multinational clinical trials. Thus, at the local level there would be a reduced impact from the obligation to continue supplying the drug to research subjects after conclusion of the study. The role of registry also requires a closer look by the field of ethics, since registries can expand the body of scientific evidence available for decision-making.

Importantly, health systems have ratified the use of economic evaluation as the principal instrument for assisting decision-making on the 
incorporation or exclusion of health technologies. This implicitly assumes that cost-effectiveness studies and their variations (cost-utility, for example) are the most widely accepted way of systematizing the evidence on healthcare costs and outcomes. However, this position does not rule out the use of other methodologies, complementary to such studies. Person Trade-Off and Rule of Rescue have been proposed as feasible complementary techniques in the decision-mak ing process. Thus, for future research we recommend the use of studies based on the Person Trade-Off method, since it allows quantifying society's preferences and values as to the allocation of scarce health resources and can support decision-makers with the incorporation or exclusion of health technologies, particularly in SUS.

\section{Resumen}

El objetivo fue sistematizar las evidencias disponibles sobre la pertinencia de utilizar la evaluación económica para la incorporación/exclusión de tecnología en enfermedades raras. Se realizó una revisión sistemática de la literatura en MEDLINE vía PubMed, CRD, LILACS, SciELO y Google Académico (literatura gris). Los estudios de evaluación económica se originan de la Economía del Bienestar, en la que los individuos maximizan sus utilidades, basándose en la eficiencia de asignación. No existe un criterio ampliamente aceptado para examinar las utilidades, a fin de dar más peso a los individuos con mayores necesidades. Generalmente, los estudios no equilibran asimétricamente las utilidades, todas son consideradas iguales, lo que en Brasil es también un principio constitucional. Los sistemas de salud han ratificado el uso de la evaluación económica como la principal herramienta para ayudar en la toma de decisiones. Sin embargo, este abordaje no excluye el uso de otras metodologías complementarias a los estudios de coste-efectividad, como la técnica de compensación personal o la regla del rescate.

Evaluación de Costo-Efectividad; Enfermedades Raras; Economía de la Salud

\section{Contributors}

E. N. Silva and T. R. V. Sousa participated in all phases of the article.

\section{Conflicts of interests}

This article is an adapted version of the technical report submitted by co-author T.R.V.S. to the National Commission on the Incorporation of Technologies by the Brazilian Unified National Health System (Conitec/ MS), for which she received funding from the institution. However, Conitec/MS did not exert any influence whatsoever on the elaboration of the article. In addition, the authors take full responsibility for the opinions expressed here. 
1. Drummond MF, Wilson DA, Kanavos P, Ubel P, Rovira J. Assessing the economic challenges posed by orphan drugs. Int J Technol Assess Health Care 2007; 23:36-42.

2. Denis A, Simoens S, Fostier C, Mergaert L, Cleemput I. Policies for orphan diseases and orphan drugs. http://ec.europa.eu/health/ph_threats/ non_com/docs/policies_orphan_en.pdf (accessed on 23/Mar/2013).

3. Drummond MF. Challenges in the economic evaluation of orphan drugs. Eurohealth 2008; 14:16-7.

4. London AJ. How should we model rare disease allocation decisions? Hastings Cent Rep 2012; 43:3-4.

5. McCabe C, Claxton K, Tsuchiya A. Orphan drugs and the NHS: should we value rarity? BMJ 2005; 331:1016-9.

6. Panju AH, Bell CM. Policy alternatives for treatments for rare diseases. CMAJ 2010; 182:E787-92.

7. Brasil. Lei no 12.401, de 28 de abril de 2011. Altera a Lei no 8.080, de 19 de setembro de 1990, para dispor sobre a assistência terapêutica e a incorporação de tecnologia em saúde no âmbito do Sistema Único de Saúde - SUS. Diário Oficial da União 2011; 29 abr.

8. European Organisation for Rare Diseases. Rare diseases: understanding this public health priority. http://www.eurordis.org/IMG/pdf/princeps_doc ument-EN.pdf (accessed on 21/Mar/2013).

9. European Union Committee of Experts on Rare Diseases. 2012 report on the state of the art of rare disease activities in Europe - Part I: overview of rare disease activities in Europe. http://www.eu cerd.eu/?post_type $=$ document $\& \mathrm{p}=1378$ (accessed on 21/Mar/2013).

10. Direcção-Geral da Saúde e da Defesa do Consumidor, Comissão Europeia. Doenças raras: os desafios da Europa. Consulta pública. Direcção C - Saúde Pública e Avaliação de Riscos. http:// ec.europa.eu/health/archive/ph_threats/non com/docs/raredis_comm_pt.pdf (accessed on 23/ Mar/2013).

11. Kaplan W, Laing R. Priority medicines for Europe and the world. http://whqlibdoc.who.int/ hq/2004/WHO_EDM_PAR_2004.7.pdf (accessed on $21 / \mathrm{Mar} / 2013$ )

12. Villarreal MA. Orphan Drug Act: background and proposed legislation in the 107th congress. http:// www.law.umaryland.edu/marshall/crsreports/ crsdocuments/RS20971.pdf (accessed on 20/ Mar/2013).

13. Office of Rare Diseases Research, National Institutes of Health. Rare diseases and related terms. http://rarediseases.info.nih.gov/ (accessed on 20/ Mar/2013).

14. Rosselli D, Rueda JD. Enfermedades raras, huérfanas y olvidadas. http://www.afidro.com/Estudio. pdf (accessed on 06/Apr/2013).

15. Agência Nacional de Vigilância Sanitária. Resolução no 16, de 13 de março de 2008. Diário Oficial da União 2008; 17 mar.

16. Souza MV, Krug BC, Picon PD, Schwartz IVD. Medicamentos de alto custo para doenças raras no Brasil: o exemplo das doenças lisossômicas. Ciênc Saúde Coletiva 2010; 15 Suppl 3:3443-54.
17. Wiest R. A economia das doenças raras: teoria, evidências e políticas públicas [Monografia]. Porto Alegre: Faculdade de Ciências Econômicas, Universidade Federal do Rio Grande do Sul; 2010.

18. U.S. Food and Drug Administration. Orphan Drug Act. Excerpts. Public Law 97-414, as amended. http://www.fda.gov/RegulatoryInformation/Leg islation/FederalFoodDrugandCosmeticActFD CAct/SignificantAmendmentstotheFDCAct/ OrphanDrugAct/default.htm (accessed on 20/ Mar/2013).

19. Hughes DA, Tunnage B, Yeo ST. Drugs for exceptionally rare diseases: do they deserve special status for funding? Q J Med 2005; 98:829-36.

20. Daines SM, Goldbaum M. Fornecimento de medicamento investigacional após o fim da pesquisa clínica - revisão da literatura e das diretrizes nacionais e internacionais. Rev Assoc Med Bras 2011; 57:710-6.

21. Cohen ERM, O'Neill JM, Joffres M, Upshur REG, Mills E. Reporting of informed consent, standard of care and post-trial obligations in global randomized intervention trials: a systematic survey of registered trials. Dev World Bioeth 2009; 9:74-80.

22. La Torre G, Nicolotti N, De Waure C, Ricciardi W. Development of a weighted scale to assess the quality of cost-effectiveness studies and an application to the economic evaluations of tetravalent HPV vaccine. J Public Health 2011; 19:103-11.

23. Perpiñán JMA, Martínez FIS, Pérez JEM. La medición de la calidad de los estudios de evaluación económica. una propuesta de 'checklist' para la toma de decisiones. Rev Esp Salud Pública 2009; 83:71-84.

24. Garber AM, Weinstein MC, Torrance GW, Kamlet MS. Theoretical foundations of cost-effectiveness analysis. In: Gold MR, Siegel JE, Russell LB, Weinstein MC, editors. Cost-effectiveness in health and medicine. New York: Oxford University Press; 1996. p. 25-53.

25. McGuire A. Theoretical concepts in the economic evaluation of health care. In: Drummond M, McGuire A, editors. Economic evaluation in health care: merging theory with practice. New York: Oxford University Press; 2001. p. 1-21.

26. Tsuchiya A, Williams A. Welfare economics and economic evaluation. In: Drummond M, McGuire A, editors. Economic evaluation in health care: merging theory with practice. New York: Oxford University Press; 2001. p. 22-45.

27. Pôrto SM. Justiça social, equidade e necessidade em saúde. In: Piola SF, Vianna SM, organizadores. Economia da saúde: conceitos e contribuição para a gestão da saúde. Brasília: Editora IPEA; 2002. p. $123-40$.

28. Nord E, Pinto JL, Richardson J, Menzel P, Ubel P. Incorporating societal concerns for fairness in numerical valuations of health programs. Health Econ 1999; 8:25-39.

29. Prades J-LP. Is the person trade-off a valid method for allocation of health care resources? Health Econ 1997; 6:71-81. 
30. Drummond MF, Sculpher MJ, Torrance GW, O'Brien BJ, Stoddart GL. Methods for the economic evaluation of health care programmes. Oxford: Oxford University Press; 2005.

31. Gold M, Siegel J, Russel L, Weinstein M. Cost-effectiveness in health and medicine. New York: Oxford University Press; 1996.

32. Ubel PA, Richardson J, Menzel P. Societal value, the person trade-off, and the dilemma of whose values to measure for cost-effectiveness analysis. Health Econ 2000; 9:127-36.

33. Arrow KJ. Uncertainty and the welfare economics of medical care. Am Econ Rev 1963; 53:941-73.

34. McKie J, Richardson J. The Rule of Rescue. Soc Sci Med 2003; 56:2407-19.
35. Silverman E. Orphan drugs: 'rare' opportunities to make money. Forbes 2012; 23 ago.

36. Diniz D, Medeiros M, Schwartz IVD. Consequências da judicialização das políticas de saúde: custos de medicamentos para as mucopolissacaridores. Cad Saúde Pública 2012; 28:479-89.

Submitted on 18/Dec/2013

Final version resubmitted on 28/May/2014

Approved on 18/Sep/2014 